\title{
Collision Frequency in Elite Hockey on North American versus International Size Rinks
}

\author{
Richard Wennberg
}

\begin{abstract}
Objective: Body impact or collision is the risk factor underlying all sports-related concussions. This study sought to determine whether collision rates in elite hockey differ between games played on North American size rinks as compared to games played on larger international size ice surfaces. Methods: Videotapes of games from the 2001 and 2002 National Hockey League Stanley Cup finals, World Junior championships and the 2002 Winter Olympics were analyzed, with all collisions counted and separated into various categories (player/player bodycheck, player/player into boards, player/boards, player/ice, head/stick, head/puck). Further subdivisions included collisions involving the head directly or indirectly. Twenty-two games were analyzed, 11 played on the small ice and 11 on the big ice. Results: Significantly more collisions of all types (in all categories and subdivisions within categories) were found to occur on the smaller North American ice surface ( $\mathrm{P}$ value differences from 0.01 to 0.00001). Conclusions: The results of this study showed significantly fewer collisions of all types in elite hockey games played on the international size ice surface. The comparison groups studied here did differ in some aspects other than ice size and so replication of the findings with even more closely matched groups will be needed before definitive conclusions can be drawn. However, if these findings are replicable, it would suggest that a change to uniform usage of the larger international rinks, with no rule changes or other alterations in the game, could provide direct primary prevention to reduce the number of collisions, and, by extension, concussions, that occur in the sport.
\end{abstract}

RÉSUMÉ: Fréquence des collisions dans le hockey élite pratiqué sur une glace de taille Nord Américaine ou de taille internationale. Objectif: La mise en échec ou la collision est le facteur de risque principal de toutes les commotions cérébrales reliées aux sports. Le but de cette étude était de déterminer si le taux de collisions dans le hockey élite était différent si la joute avait lieu sur une patinoire de taille Nord Américaine ou sur une patinoire plus grande, soit de taille internationale. Méthodes: Nous avons analysé les bandes vidéo de parties de la série finale de la Coupe Stanley de la Ligue nationale de hockey 2001 et 2002, du Championnat junior mondial et des Jeux olympiques d'hiver 2002. Toutes les collisions ont été comptées et réparties en différentes catégories (mise en échec joueur/joueur, joueur/joueur/bande, joueur/bande, joueur/glace, tête/bâton, tête/rondelle), avec subdivision selon que la tête était directement ou indirectement impliquée. Vingt-deux parties ont été analysées, soit 11 jouées sur une glace de petite taille et 11 sur une glace de grande taille. Résultats: Un nombre significativement supérieur de collisions de tous types (de toutes catégories et subdivisions) ont été observées pendant les joutes jouées sur la glace de petite taille, selon les règles Nord américaines $(\mathrm{p}=0,01$ à 0,00001$)$. Conclusions: Les résultats de cette étude démontrent qu'il y a significativement moins de collisions de tous types pendant les joutes de hockey élite jouées sur une glace de taille internationale. Les groupes comparés étaient différents sous certains autres aspects. Il sera donc nécessaire de corroborer ces résultats par l'étude de groupes plus semblables pour tirer des conclusions définitives. Cependant si nos observations sont reproductibles, l'utilisation de glaces de taille internationale, sans changement de règlements ou autre modification du jeux pourrait constituer une prévention primaire directe pour réduire le nombre de collisions et ainsi de commotions cérébrales qui surviennent au hockey.

Can. J. Neurol. Sci. 2004; 31: 373-377

The problem of sports-related concussions has garnered increased attention from the medical community in recent years. A recently published summary statement from the 1st International Symposium on Concussion in Sport has outlined the scope of the problem, the limits of current knowledge and the
From the Division of Neurology and Krembil Neuroscience Centre, Toronto Western Hospital, University Health Network, University of Toronto, Toronto, ON, Canada. ReCEIVED July 29, 2003. ACCEPTEDin FinAlForm JANUARY 15, 2004.

Reprint requests to: Richard Wennberg, Toronto Western Hospital, 399 Bathurst Street, 5W444, Toronto, ON, Canada M5T2S8 
need for future developments in research, treatment and prevention. ${ }^{1}$ Efforts to improve prevention are especially important for concussion given the potential cognitive and behavioral sequelae of this injury and the current absence of effective medical treatment.

Body impact or collision is the risk factor underlying all sports-related concussions. Therefore, interventions to decrease collision rates would provide the most direct means of primary prevention of concussion. In hockey, one may predict that fewer collisions would occur in games played on larger ice rinks. This hypothesis can be tested by analyzing collision rates in games played on North American (National Hockey League, (NHL)) size rinks and comparing these to collision rates in games played on international size rinks, where the playing surface is more than 3000 square feet larger. This paper presents the results of such an analysis of elite hockey, performed using videotapes of games from the 2001 and 2002 NHL Stanley Cup finals, World Junior championships and the 2002 Winter Olympics.

All body impacts were counted and subdivided into volitional, incidental or accidental collisions of players with other players, the boards and glass, the ice, sticks or pucks. Collisions were further subdivided into those involving the head directly or indirectly (the latter involving acceleration/deceleration or torsional head movements secondary to initial body impact). Significantly more collisions of all types were found to occur on the smaller rinks.

\section{Methods}

Videotapes of televised broadcasts for the following games were available for review: all five games from the NHL 2002 Carolina - Detroit Stanley Cup finals (Canadian Broadcasting
Corporation, (CBC)), all seven games from the 2001 NHL New Jersey - Colorado Stanley Cup finals (CBC), ten games from the 2002 Winter Olympics hockey competition including all six games involving Canada (CBC), the USA- Russia semifinal and Belarus - Russia bronze medal games (CBC) and the USA Finland and USA - Russia preliminary round games (National Broadcasting Company, (NBC)). All five games from the Carolina - Detroit series and the first five games of the New Jersey - Colorado series were analyzed, excluding overtimes. In the comparative group, the ten available games from the 2002 Winter Olympics were analyzed. In addition, videotapes of the Canada - Russia gold medal games from the 2001 and 2002 World Junior championships were analyzed (The Sports Network, (TSN)). Thus a total of 22 games were analyzed, 11 played on the NHLsize rink (all Stanley Cup games and the 2002 World Junior championship game) and 11 played on the larger international size rink (all games from the 2002 Olympics and the 2001 World Junior championship game).

All impacts were counted as collisions with the aim of eliminating subjectivity in grading hits as significant or insignificant. However, body contact between players without impact per se (for example, players in checking contact with one another while skating in the same direction) was not counted.

Collisions were separated into different categories. The largest category by far was "player/player bodycheck (including stickcheck)." This category was subdivided into volitional and accidental groups, with collisions in the latter group exceedingly rare. The volitional group was further subdivided into open ice bodychecks and "player/player into boards (and glass)." The other categories were: "player/ice" collisions, subdivided into accidental or incidental (mainly tripping) groups; "player/boards"

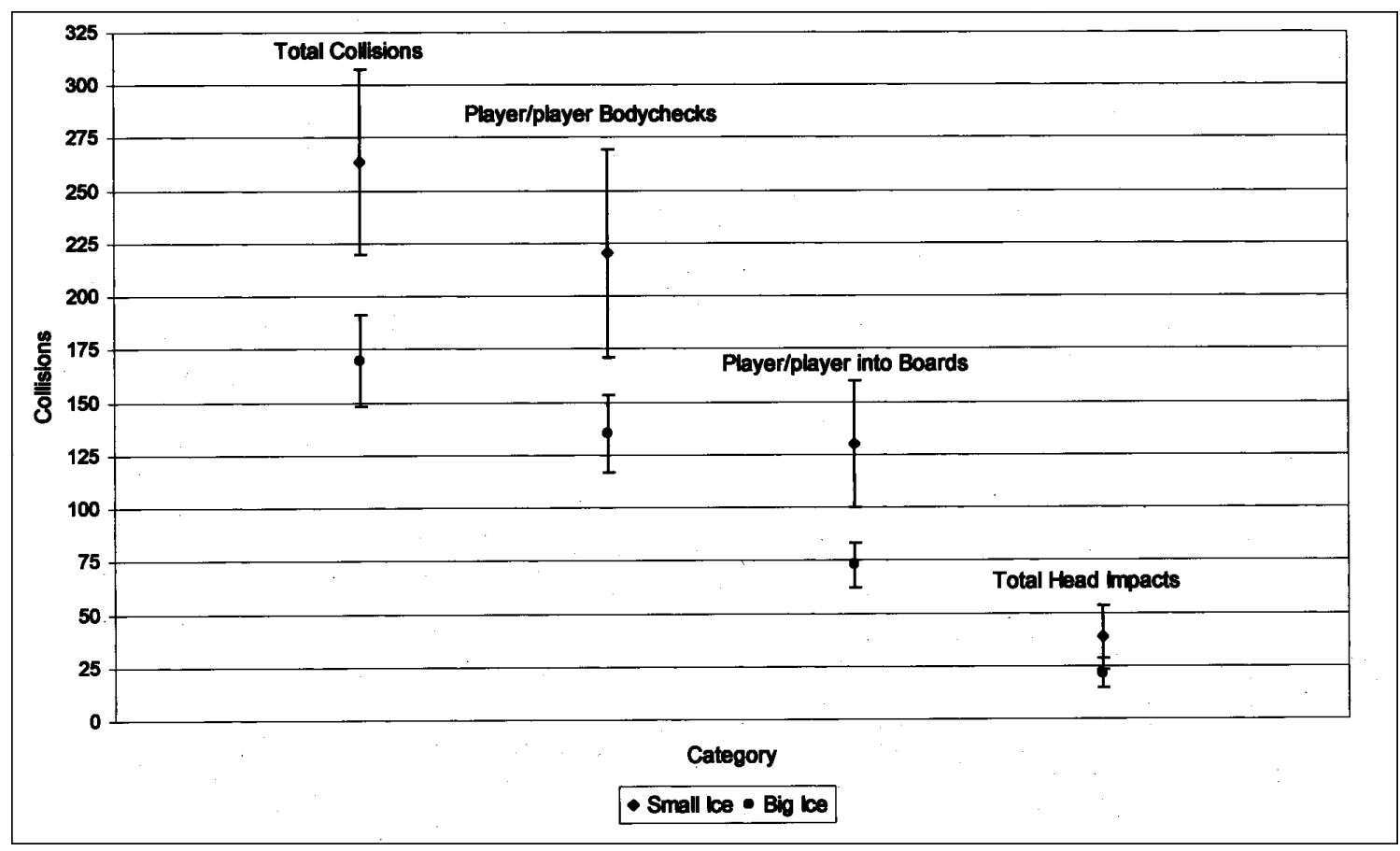

Figure: Differences in frequency of collisions per game in games played on the small North American ice surface versus the big international ice surface. Significantly more collisions of all types occurred on the small ice. 


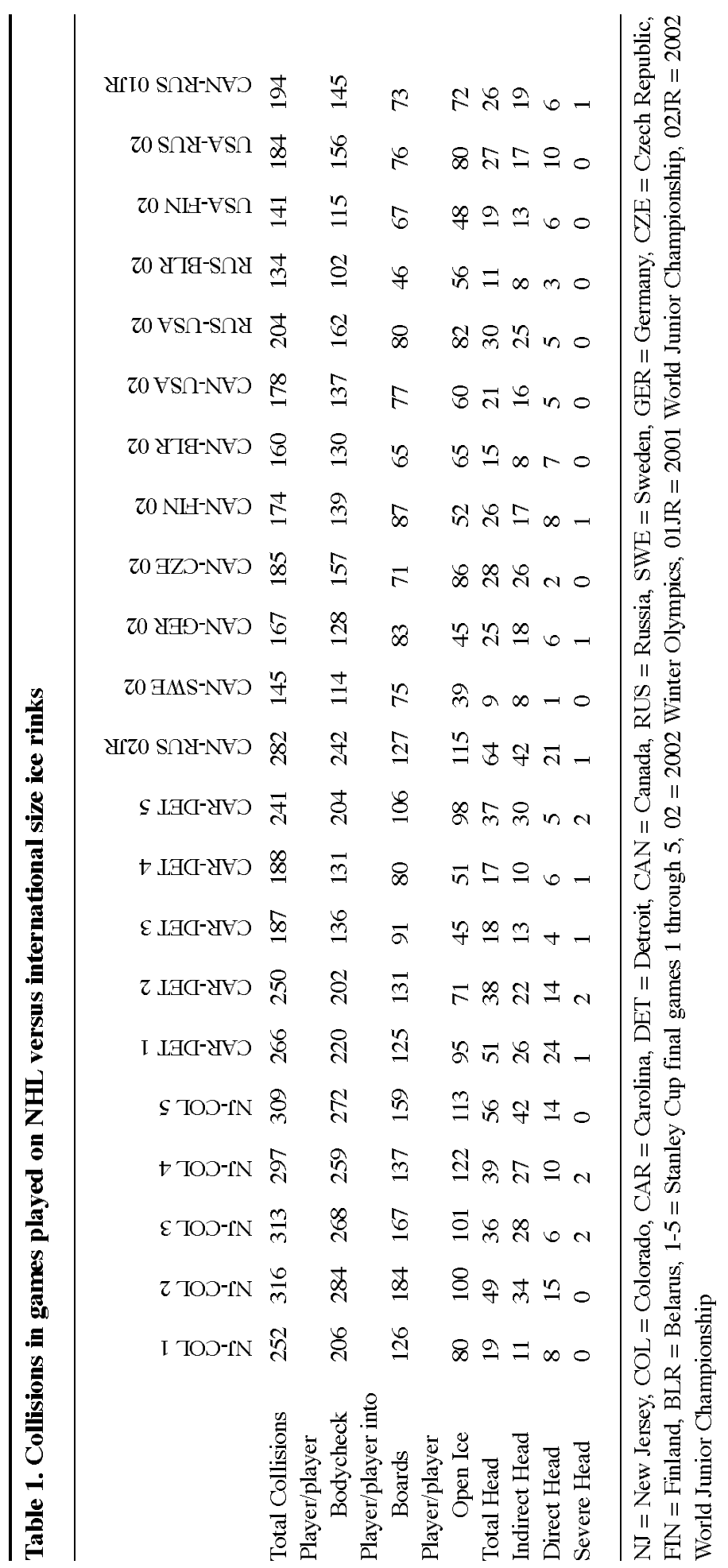

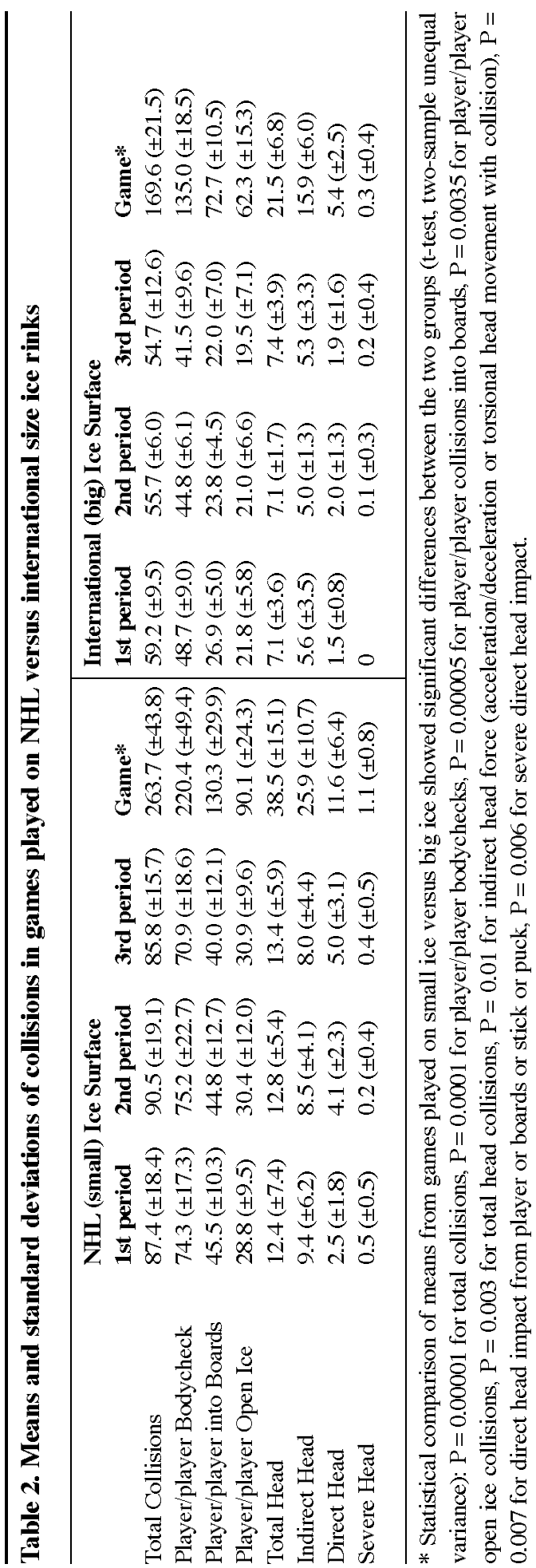


collisions, subdivided into accidental or incidental groups; direct "head/stick" impacts (accidental or incidental, e.g. resulting from lifting the stick); and "head/puck" impacts.

The "player/player bodycheck," "player/ice" and "player/boards" categories were further subdivided to separate collisions involving the head into "indirect head" impacts (referring to acceleration/deceleration or torsional head movements resulting from initial body impact) and "direct head" impacts (in the open ice player/player body check category this referred to direct blows to the head from another player's shoulder, elbow, etc., while in the player/player into boards group this referred to a direct impact of the head into the boards and/or glass). A final subdivision of "severe head" impact was used to denote obvious, unusually severe blows to the head in any category.

Statistical analyses of differences used the t-test, two sample for unequal variances.

\section{RESUltS}

A summary of the raw data per game is presented in Table 1. Means and standard deviations of collisions per game in the different categories are presented in Table 2. Also shown in Table 2 are means and standard deviations of collisions separated by period of occurrence. There were slightly fewer total collisions and slightly more total head impacts on average in the third periods of games played on both the big and small ice surfaces, but no significant differences between the periods.

Statistical comparisons of the mean number of collisions per game in all categories showed highly significant differences with fewer collisions of all types occurring in games played on the larger international size ice surface (Table 2, Figure).

The vast majority of total collisions were in the volitional player/player category. Accidental collisions of all sorts (player/player, player/ice, player/boards, head/stick or head/puck) were responsible for a minority of total impacts (less than 10 percent). Incidental collisions (mainly player/ice associated with tripping) made up the remainder.

With respect to impacts indirectly involving the head, on the NHL ice surface 58 percent $(165 / 284)$ resulted from player/player into boards collisions, 40 percent (114/284) from player/player collisions and 2 percent (5/284) from other mechanisms (two cases incidental player/boards and one each of incidental player/ice, accidental player/player and accidental player/boards). On the international ice surface, the corresponding breakdown of mechanisms was similar: 56 percent (97/174) player/player into boards, 41 percent $(71 / 174)$ player/player and 3 percent (6/174) other (three cases incidental player/boards and one each of incidental player/ice, accidental player/player and accidental player/boards).

With respect to direct head impacts, on the NHL ice surface 54 percent (69/127) resulted from player/player into boards collisions, 38 percent (48/127) from player/player collisions and 8 percent (10/127) from other mechanisms (eight cases of accidental or incidental head/stick and one each of accidental player/player and head/puck). On the international ice surface, the corresponding breakdown of mechanisms was relatively similar: 46 percent (28/61) player/player into boards, 36 percent (22/61) player/player and 18 percent other (10 cases of accidental or incidental head/stick and one case where a player/player bodycheck resulted in a direct head impact with the crossbar of the goal).

Finally, with respect to severe head impacts, on the NHL ice surface 58 percent (7/12) resulted from player/player into boards collisions, 33 percent (4/12) from player/player collisions and 8 percent (1/12) other (a single case of head/puck impact). On the international ice surface, two of the three severe head impacts resulted from player/player into boards collisions and the other from a player/player collision.

\section{Discussion}

The international ice surface is 15 feet wider and four feet longer than the standard 200 feet $\times 85$ feet dimensions of a North American NHLrink. Thus there is more than 3000 square feet of extra room for players to maneuvre on the big ice surface. This difference in size of the ice rinks is presumably the major factor accounting for the significant differences in rate of occurrence of all types of collisions, including those affecting the head, seen in this study when comparing games played on the North American size rinks and games played on the larger international size rinks. The extra room on the big ice renders it physically more difficult for players to collide and, to some extent, players may deliberately change their approach to hitting based on ice size. Any such change would likely represent a matter of necessity (for example, for defencemen to avoid being caught out of position) rather than a change of volition.

It must be acknowledged that a number of other factors may also have contributed to the differences in collision rates in games played on the big ice and small ice. Specifically, the games played in the Winter Olympics used the "no redline," "no touch icing" and "fast face-off" rules, all of which may have served to decrease the possibility for aggressive play and collision occurrence by spreading out defensive formations and speeding up the pace of the game. In addition, the best of seven series format of the NHL Stanley Cup finals may be more conducive to aggressive play with a resultant increase in collisions from attempts to "set the tone" through intimidation for upcoming series games. The individual game format and sudden death eliminations in the Olympics competition may limit such attempts to "set the tone" for subsequent games as the possibility of early elimination from tournament play may limit aggressivity and its attendant risk of penalization. Furthermore, in a more general sense, there is the potential for an overall more aggressive style of play in the NHL driven by the presumed "marketability" of violence in the professional North American league, with the existence of aggressive "role players" on NHL teams whose livelihoods depend on their aggressivity, players certainly underrepresented among those selected to play for their respective countries in the Olympics. However, these variables in rules, format and style were eliminated as differences in the big ice versus small ice analysis of the Canada - Russia World Junior hockey championship gold medal games. Here, the ice size difference was clearly the main variable differentiating the 2001 and 2002 games and the collision results in these two games were entirely typical of the group as a whole. These findings support the presumption that the significant differences seen in collision rates between the NHL and Winter Olympics games are mainly related to the differences in ice size. 
Most of the videos of games analyzed were from CBC broadcasts, both on the large ice and the small ice, and the camera coverage used by $\mathrm{CBC}$ at the Olympics competition was as extensive as ever used for hockey broadcasts, arguing against any systematic bias in the number of collisions seen on video related to differences in camera coverage. The two TSN broadcasts of the World Junior games were balanced with one game on the big ice and one game on the small ice. The only asymmetry was the inclusion of the two NBC broadcasts of the USA Olympic competition preliminary round games (against Finland and Russia): the striking similarity of collision numbers in these two games compared to those in the other nine games played on the international ice surface would argue against any important bias on this count.

The results showed significantly fewer collisions of all types in games played on the larger ice surface. Intuitively, one might have expected to see the greatest difference in the player/player into boards collision category, given that the difference in dimensions between the two ice surfaces is most notable for increasing the distance between the side boards running the length of the rinks. And indeed, the Pvalue differences did show a greater significance for the player/player into boards category than for the open ice player/player bodycheck category.

This study made no attempt to relate the actual number of concussions incurred during these 22 games with ice size. The relevant medical information was not available for study and, in any event, the number of concussions expected to occur in 22 elite level games would be too low to allow for meaningful comparisons (for NHLgames concussion rates over the past five years have averaged less than one per 25 games). ${ }^{2}$ There is only one published study that has specifically examined the association between ice size and injury and that study did not compare the North American size rinks versus the much larger international size rinks but, instead, compared games played in the Ontario major junior league on standard NHL size rinks with games played on some rinks in the league that are substandard in size. $^{3}$ Even though the ice size differences in that study were relatively minor, the incidence of injury (of all types) was shown to be inversely correlated with rink size.

Recommendations have arisen from within the medical community to consider restricting bodychecking in hockey to limit collisions and reduce the risk of concussions. ${ }^{4}$ Although it must be emphasized that the present study is a first, preliminary analysis that will need to be replicated with even more closely matched comparison groups (for example, future World Junior championship series), another option to limit collisions, supported by the findings of this study, would be to uniformly enlarge the playing surface. The same effect of reduced collisions would presumably also accrue from reducing the number of players on the ice, for example, switching to "four on four" play. However, the latter change would significantly alter the nature of the game. Hockey is already well-established as an elite sport played on either of two ice sizes. If the findings of this study are replicable, it would suggest that a change to uniform usage of the larger international ice surface, with no rule changes or other alterations in the game, could provide direct primary prevention to reduce the number of collisions, and, by extension, concussions, that occur in the sport.

\section{REFERENCES}

1. Aubry M, Cantu R, Dvorak J, et al. Summary and agreement statement of the 1st International Symposium on Concussion in Sport, Vienna 2001. Clin J Sport Med 2002; 12: 6-11.

2. Wennberg RA, Tator $\mathrm{CH}$. National Hockey League reported concussions, 1986-87 to 2001-02. Can J Neurol Sci 2003; 30: 206-209.

3. Watson RC, Nystrom MA, Buckolz E. Safety in Canadian junior ice hockey: the association between ice surface size and injuries and aggressive penalties in the Ontario Hockey League. Clin J Sport Med 1997; 7: 192-195.

4. Marchie A, Cusimano MD. Bodychecking and concussions in ice hockey: Should our youth pay the price? Can Med Assoc J 2003; 169: 124-128. 